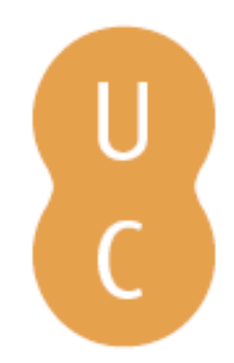

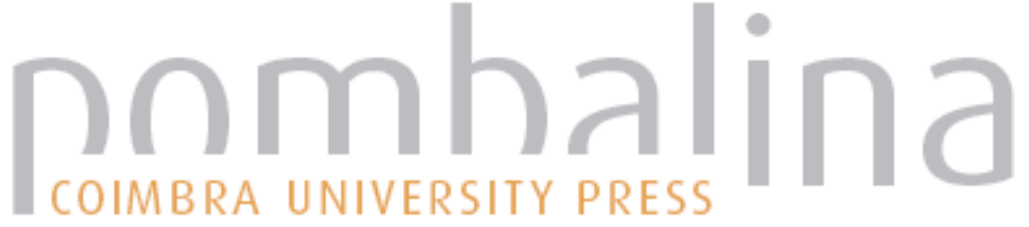

\section{Viver Albufeira: avaliação de efeitos do programa Polis}

\author{
Autor(es): $\quad$ Marreiros, Aquiles
}

Publicado por: Imprensa da Universidade de Coimbra

URL

persistente: URI:http://hdl.handle.net/10316.2/30763

DOI: $\quad$ DOI:http://dx.doi.org/10.14195/978-989-26-0244-8_12

Accessed : $\quad$ 26-Apr-2023 10:31:07

A navegação consulta e descarregamento dos títulos inseridos nas Bibliotecas Digitais UC Digitalis, UC Pombalina e UC Impactum, pressupõem a aceitação plena e sem reservas dos Termos e Condições de Uso destas Bibliotecas Digitais, disponíveis em https://digitalis.uc.pt/pt-pt/termos.

Conforme exposto nos referidos Termos e Condições de Uso, o descarregamento de títulos de acesso restrito requer uma licença válida de autorização devendo o utilizador aceder ao(s) documento(s) a partir de um endereço de IP da instituição detentora da supramencionada licença.

Ao utilizador é apenas permitido o descarregamento para uso pessoal, pelo que o emprego do(s) título(s) descarregado(s) para outro fim, designadamente comercial, carece de autorização do respetivo autor ou editor da obra.

Na medida em que todas as obras da UC Digitalis se encontram protegidas pelo Código do Direito de Autor e Direitos Conexos e demais legislação aplicável, toda a cópia, parcial ou total, deste documento, nos casos em que é legalmente admitida, deverá conter ou fazer-se acompanhar por este aviso.

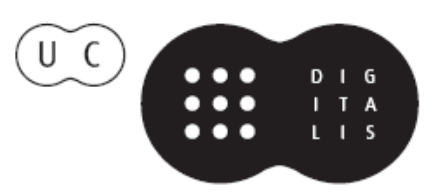




\section{TRUNFOS DE UMA}

\section{EOGRAFIA ACIVA}

\section{DESENVOLVIMENTO LOCAL,}

AMBIENTE,

ORDENAMENTO

E TECNOLOGIA

Norberto Santos

Lúcio Cunha

COORDENAÇÃO 
Aquiles Marreiros

Municipio de Albufeira

VIVER ALBUFEIRA - AVALIAÇÃO DE EFEITOS DO PROGRAMA POLIS

\section{De Vila Piscatória a CAPITAL do TURISMO}

Cidade Turística por excelência, Albufeira é desde os anos 70, o centro de animação e atracção turística mais importante e internacionalizado do Algarve. A história desta cidade está intimamente ligada à história do turismo em Portugal, sobretudo desde os anos 50 . Num contexto de recessão económica e com o declínio das actividades industriais associadas ao mar, o turismo foi projectado como uma nova vocação regional. A descoberta de Albufeira pelo turismo nacional nasce com a instalaçáo da unidade de turismo social da FNAT, hoje INATEL, no ano de 1958. A abertura do aeroporto de Faro em 1965 abriu as portas ao turismo internacional e potenciou a procura regular da regiáo sobretudo por turistas ingleses. Albufeira afirmou-se como destino de eleição de muitos desses turistas, entre eles alguns artistas de renome, cuja presença muito contribuiu para a projecção do destino além fronteiras (Ministério do Ambiente e Ordenamento do Território e Câmara Municipal de Albufeira 2000). Nos anos 70 Albufeira conheceu um grande desenvolvimento económico e demográfico passando de uma pacata vila piscatória ao mais importante destino turístico do país, posiçáo mantida até aos dias de hoje, comprovada pela expressividade dos indicadores do INE referentes ao ano 2007: 78 \% de populaçáo empregada no sector terciário, $34 \%$ da oferta dos estabelecimentos hoteleiros, $41 \%$ da capacidade de alojamento, $44 \%$ das dormidas e $39 \%$ dos hospedes em estabelecimentos hoteleiros, números que lhe valem o título de capital do turismo e o reconhecimento do destino a nível nacional e internacional. A economia local encontra-se fortemente terciarizada e especializada no sector turístico e nas cadeias de valor a ele associadas. Contudo a massificação da procura motivou o crescimento urbanístico, desregrado e de pouca qualidade arquitectónica. A cidade turística de Albufeira vive simultaneamente processos de expansão e desqualificação.

\section{Programa Polis - ViVER AlbufEIRA}

Promovido pelo Ministério do Ambiente e do Ordenamento do Território, o Programa Polis tem por objectivo geral melhorar a qualidade de vida nas cidades, através de intervençóes de carácter urbanístico e ambiental, aumentando a sua atractividade e competitividade no Sistema Urbano Nacional (RCM n. ${ }^{\circ}$ 26/2000, de 15 de Maio). A intervenção de Albufeira explanada no Plano Estratégico - Viver Albufeira 2000 incidia sobre 
uma área de 258 hectares e tinha como objectivo central Reforçar e valorizar Albufeira como principal centro de animação urbano-turística do Algarve. Enquanto cidade/destino turístico maduro, em processo crescente de desqualificação, pretendia-se promover um conjunto de acçóes que contribuísse para a valorização da imagem e para o fortalecimento da marca turística que constituía. Estimava-se um investimento global de 48,7 milhóes de Euros. Para a concretização do objectivo central, a intervençáo Polis de Albufeira previa a prossecução de sete objectivos específicos: 1) Requalificação ambiental e urbanística no centro antigo assumindo-se como elemento estruturante da cidade turística, 2) Reordenamento da malha viária, permitindo a criaçáo de um amplo espaço pedonal no centro antigo e frente urbana litoral, 3) Reforço e valorizaçáo da estrutura verde da cidade, 4) Valorização das praias e da frente urbana litoral, 5) Recuperação de valores arquitectónicos existentes, integrando-os em projectos urbanos de referência, 6) Reestruturaçáo urbana visando criar espaço público e 7) Recuperação de estruturas urbanas desactivadas dando-lhes um outro uso. Paralelamente promoveu-se uma ampla estratégia de comunicaçáo que pretendia não só dar conhecimento das acçóes a empreender no espaço urbano, como desafiava os cidadáos a reflectir conjuntamente sobre as diversas disciplinas da envolvente ambiental.

O Polis Albufeira continha três eixos estratégicos: i) valorizar o centro antigo como centro de animação urbano-turística, ii) ampliar e requalificar o espaço balnear de Albufeira e iii) garantir a sustentabilidade urbana do centro antigo e da frente de mar, cuja operacionalização passava pela concretizaçáo de quatro projectos estruturantes: 1) Centro Antigo, 2) Nova Praia de Albufeira, 3) Zona Poente de Albufeira e 4) Anel Verde, Pedonal e Ciclável, contemplado conjuntamente 41 acçóes. Destas foram concretizadas $66 \%$, estando $12 \%$ em fase de projecto ou construção/execuçáo e $22 \%$ por realizar. Contudo, os projectos estruturantes possuem pesos diferenciados no quadro da estratégia, por exemplo o projecto do Centro Antigo pressupunha a realização de 27 acçóes, enquanto a Zona Poente de Albufeira continha apenas 3. Todas elas impulsionavam a forma de pensar a cidade, que se pretendia requalificada, valorizada, sustentada e participada por todos. O Plano Estratégico foi pouco ambicioso na definiçáo de metas, delineando-as em duas áreas distintas: ambientais e socioeconómicas. Nas primeiras há a registar o incumprimento do acréscimo de 10 hectares de área verde disponível e a construçáo do Centro de Monitorização e Interpretação, ambas, marcantes ao nível ambiental e no quadro da estratégia global, o que, só por si, influenciou a avaliação dos eventuais efeitos causados nesta área. As restantes metas, acréscimo de $25.000 \mathrm{~m}^{2}$ de área de trânsito condicionado, $12.500 \mathrm{~m}^{2}$ de extensão pedonalizada, $15.000 \mathrm{~m}^{2}$ de novas praças, a criação de 950 lugares de estacionamento ou a criação de $1 \mathrm{~km}$ de ciclovia, foram bem sucedidas e algumas superadas. Nas metas socioeconómicas, há a destacar o trabalho necessário e contínuo, para que algumas possam vir a ser atingidas, nomeadamente a reabilitação do centro antigo motivando a atracção de novas geraçóes ou a melhoria dos desempenhos das actividades económicas urbanas, as quais não dependiam exclusivamente das intervençôes preconizadas, assim como demorará algum tempo a identificá-las como consequência directa do Polis. Destaque para o incumprimento das metas ao nível do emprego, eventualmente mal aventadas, pois não resultavam de quaisquer acçóes específicas que fomentassem a oferta de emprego no domínio do ambiente ou de emprego qualificado, pelo que seriam de difícil concretização. No entanto atingiramse metas ao nível da dinamização turística, reconversão de edifícios degradados e valorização de equipamentos culturais e de lazer. 


\section{AVALIAÇÃO DE EFEITOS}

A avaliação do Programa Polis incidiu nos efeitos causados em diferentes domínios tematicos - Requalificação Urbana, Ambiente e Espaços Verdes, Turismo e Animação, Economia e Emprego, Mobilidade, Circulação e Estacionamento, Património e Governança e Comunicação definidos com base no referencial do próprio Plano Estratégico, objectivos, eixos, projectos estruturantes e acçóes. Implementaram-se inquéritos e entrevistas junto de quatro grupos distintos - 1) Administração/promotores (Município, Junta de Freguesia de Albufeira e Sociedade POLIS), 2) APAL, responsável pela promoção turística e ACRAL, AHETA e AHRESP, associaçóes representativas dos comerciantes, dos hotéis e empreendimentos turísticos e dos Restaurantes e Bares, os próprios comerciantes, dirigentes hoteleiros e proprietários ou gerentes de bares e restaurantes, 3) Populaçáo Residente e 4) Turistas. Com os inquéritos pretendia-se evidenciar os indicadores/descritores qualitativos, que, posteriormente e de forma complementar, seriam validados com recurso a análise documental e a indicadores de execuçáo física e quantitativa resultantes das acçóes e metas concretizadas.

Figura 1 - Avaliação de Efeitos por domínios e tipologia de inquiridos

\begin{tabular}{|c|c|c|c|c|c|c|c|c|c|c|c|c|c|c|c|c|c|}
\hline \multicolumn{4}{|c|}{ Domínios } & & & & & & & & & & & & & & \\
\hline \multicolumn{4}{|c|}{ Re qua lific ação Urbana } & & ++ & O & + & - & + & - & + & + & $\mathrm{O}$ & $\mathrm{O}$ & + & + & + \\
\hline \multicolumn{4}{|c|}{ Ambiente e Espaços Verdes } & & + & + & ++ & -- & - & $\mathrm{O}$ & + & $\mathrm{O}$ & $\mathrm{O}$ & - & + & + & - \\
\hline \multicolumn{4}{|c|}{ Turismo e Animação } & & + & ++ & O & $\mathrm{O}$ & - & O & O & O & $\mathrm{O}$ & O & + & + & O \\
\hline \multicolumn{4}{|c|}{ Economia e Emprego } & & + & - & - & - & - & - & - & $\mathrm{O}$ & - & -- & - & - & - \\
\hline \multicolumn{4}{|c|}{ Mobilidade, Circulação e Es tacionamento } & & + & ++ & ++ & + & - & + & + & + & $\mathrm{O}$ & + & + & + & + \\
\hline \multicolumn{4}{|l|}{ Património } & & + & + & - & - & - & - & $\mathrm{O}$ & $\mathrm{O}$ & - & - & + & + & - \\
\hline \multicolumn{4}{|c|}{ Governança e Comunicação } & & + & - & - & -- & $\mathrm{O}$ & - & - & $\mathrm{O}$ & & - & - & & - \\
\hline \multicolumn{4}{|c|}{ Avaliação Global } & & + & + & - & - & - & - & + & $\mathrm{O}$ & $\mathrm{O}$ & - & + & + & - \\
\hline \multicolumn{4}{|c|}{ Apreciação global } & & + & + & + & $\mathrm{O}$ & $\mathrm{O}$ & O & + & $\mathrm{O}$ & $\mathrm{O}$ & $\mathrm{O}$ & + & + & + \\
\hline \multicolumn{4}{|c|}{ \% Efeitos Positivos } & NA & 80 & 58 & 47 & 25 & 24 & 29 & 33 & 44 & 7 & 29 & 53 & 44 & 53 \\
\hline- & Muito Mau & - & Mau & $\mathbf{o}$ & Razo & ivel & + & Bom & ++ & & ito $\mathrm{E}$ & om & & $\mathrm{NS} / \mathrm{l}$ & & & \\
\hline
\end{tabular}

Ao inquérito responderam 88 indivíduos, em representação própria ou de entidades ou agentes económicos, $46 \%$ foram respondidos por população residente, $27 \%$ por representantes das associaçóes, dos estabelecimentos comerciais, hoteleiros e restaurantes, $25 \%$ respondidos por turistas. E os restantes por representantes da administração local. Convidada a participar a Sociedade Polis facultou os dados e informaçóes solicitadas mas não respondeu ao inquérito. Dos inquiridos $53 \%$ foram homens e $47 \%$ mulheres, destes prevalecem os indivíduos com idades compreendidas entre os 25 e os 40 anos, com cerca de $36 \%$, sendo este grupo seguido por $32 \%$ de indivíduos com idades entre os 40 e os 55 anos. Cerca de 38 $\%$ possui habilitaçóes ao nível do $3 .^{\circ}$ ciclo de ensino, $29 \%$ com ensino superior, $17 \%$ com $10^{\circ}$ ciclo, $8 \%$ com $2 .^{\circ}$ ciclo e também $8 \%$ com ensino secundário. Dos turistas entrevistados, $27 \%$ eram portugueses e os restantes estrangeiros - $32 \%$ de irlandeses, $18 \%$ de ingleses, $14 \%$ de alemães e $9 \%$ de holandeses. Da totalidade dos turistas, $44 \%$ visitava 
Albufeira pela primeira vez, o que pode ter influenciado as avaliaçóes registadas, uma vez que não existiam padrôes comparativos, nem o conhecimento da cidade antes da intervençáo do Programa Polis. $77 \%$ pretendia voltar a Albufeira e os mesmos $77 \%$ recomendavam-na como destino de férias. Foi solicitada a avaliaçáo de 60 parâmetros, agrupados nos sete domínios temáticos mencionados. A avaliação compreendia uma escala apreciativa dos efeitos com as seguintes hipóteses de resposta: muito mau, mau, razoável, bom, muito bom e não sabe/não responde. Os parâmetros definidos resultavam não só da acção de gestão e coordenação da Sociedade Polis, mas sobretudo da actuação conjunta desta com o Município de Albufeira que reunia competências essenciais para a prossecução dos objectivos. Optou-se por abordar os parâmetros e domínios temáticos relevantes na implementação da estratégia, independentemente de quem os promovia ou concretizava.

A apreciação global dos efeitos causados pelo Polis em Albufeira foi tendencialmente positiva, tendo as respostas incidido nas opçōes bom ou razoável. Esta apreciação foi mais favorável do que as avaliaçóes registadas, quer nos domínios quer nos parâmetros. Nota para a sintonia observada nas avaliaçóes globais quer das associaçóes quer dos respectivos associados. Já ao nível dos parâmetros, esta sintonia dissipa-se pois os comportamentos avaliativos revelam diferenças substanciais, apresentando as associaçôes, avaliações menos favoráveis que os seus associados. De uma forma geral os efeitos mais positivos foram sentidos pela administração pública local, Município e Junta de Freguesia de Albufeira, com 80 \% e 58 \% respectivamente de efeitos avaliados favoravelmente dentre os parâmetros possíveis. A estas junta-se a avaliaçáo positiva manifestada pelos turistas e pelos residentes, o que só por si constitui um importante indicador de satisfação com os trabalhos desenvolvidos, sendo estes os principais públicos beneficiários desta estratégia. Inversamente, as piores avaliaçóes de efeitos gerados foram efectuadas pela AHRESP, ACRAL, comerciantes e APAL, respectivamente com $58 \%$, $47 \%$ e os dois últimos com $40 \%$ dos parâmetros a registarem avaliaçóes negativas. $\mathrm{O}$ grupo de inquiridos que registou menos efeitos positivos foi o dos bares, com apenas $7 \%$ dentre os possíveis. $\mathrm{Na}$ avaliação dos efeitos por domínios temáticos evidencia-se a apreciação positiva registada pela maioria dos inquiridos na Requalificaçáo Urbana e Mobilidade, Circulação e Estacionamento. Pelo contrário com apreciaçóes globalmente negativas, temos os domínios de Economia e Emprego, Património, Governança e Comunicação e Ambiente e Espaços Verdes.

No domínio da Requalificação Urbana apenas a ACRAL considerou que grande parte dos parâmetros avaliados tenha produzido efeitos negativos. A criação de miradouros e a pedonalização da baixa reúnem o consenso dos inquiridos em termos de efeitos positivos gerados. Pelo contrário, com pior desempenho temos parâmetros como a reutilização de edifícios degradados ou devolutos e a sinalética informativa e direccional. Neste domínio o Polis propunha-se intervir em escalas distintas com alcances diferenciados, desde o ordenamento e planeamento do território até intervenções específicas no espaço público, como a remodelação de praças e arruamentos. $\mathrm{Na}$ área de intervenção resultaram três instrumentos de gestão territorial distintos - o Plano de Urbanização da Frente de Mar da Cidade de Albufeira (RCM n. ${ }^{0}$ 159/2003, de 6 de Outubro), o Plano de Pormenor da Praça dos Pescadores (Deliberaçáo n. ${ }^{\circ}$ 213/2008, de 25 de Janeiro) e o Plano de Urbanização da Cidade de Albufeira, em elaboração. A maior parte das acções incidentes ao nível da requalificação urbana foi executada com sucesso, existindo porém, fortes críticas aos materiais empregues, referenciados por $16 \%$ dos inquiridos, como desajustados para as intervençóes. 
Com a actividade económica dominante assente na fruição de espaços ambientais, sobretudo das praias, o domínio Ambiente e Espaços Verdes assumia-se como primordial na estratégia. As intervençóes centraram-se na valorização e requalificação das praias, quer pela sustentação e protecção das arribas intervencionadas em 2003, quer pela alimentação dos areais das praias urbanas, iniciada em Outubro de 2009. Destaque para os efeitos positivos registados nos parâmetros afectos à limpeza do espaço público e das praias, motor da atracção turística. Inversamente, a criaçáo e manutenção de espaços verdes merece nota negativa por parte dos avaliadores, para a qual poderá ter contribuído a náo concretizaçáo do Parque de Vale Mangude. No que respeita às acçóes de sensibilizaçáo, informação e de educação ambiental, estas não chegaram ao conhecimento da maioria dos inquiridos e tiveram um alcance restrito junto do público escolar.

Embora sem acçóes específicas enquadradas no domínio Turismo e Animação, a maioria delas revertia a seu favor, sendo esperados efeitos de várias ordens. Lembra-se que o objectivo do Polis era potenciar Albufeira como principal centro de animaçáo urbano-turística do Algarve, pretendendo-se evidenciar neste ponto a atractividade, dinâmica e animação gerada pelo conjunto de intervençóes efectuadas. Em 2003 foi elaborado o Plano de Valorização Turística de Albufeira, documento estratégico que materializava um quadro de orientaçóes e referências para a actuação concertada de entidades públicas e privadas ligadas ao sector turístico. Em 2004 foi criada a Agência de Promoção de Albufeira, associação sem fins lucrativos composta pelo Município e por empresas do concelho, cujo principal objectivo era promover e divulgar os produtos turísticos de Albufeira e os seus produtos regionais através de acçóes específicas direccionadas para os mercados internos e externos. Quer a APAL quer o Município esforçaram-se por captar novos mercados recorrendo a formas de promoção e marketing urbano, road show, participação em feiras da especialidade junto dos mercados de proximidade, interno e Espanha. As brochuras promocionais reflectiram as mudanças sentidas na cidade, fazendo mençóes à renovação da mesma e ao entrosamento do centro antigo com laivos de modernidade, evidenciando também sub produtos turísticos associadas à prática balnear, nomeadamente a animação, desporto, compras e gastronomia. Estas são editadas em cinco línguas (português, alemão, inglês, castelhano e francês) e difundidas nas cerca de dez feiras em que Albufeira participa anualmente, seis delas internacionais. $\mathrm{O}$ alcance desta estratégia observa-se já no aumento dos turistas nacionais em Albufeira, que no ano 2000 correspondia a $20 \%$ e em 2007 já representava cerca de $25 \%$. Também o mercado espanhol apresenta sinais de crescimento favoráveis, tendo passado de apenas $2 \%$ para mais de $6 \%$. No que respeita à animação turística, veja-se a título de exemplo o número de eventos realizados na nova Praça dos Pescadores que em 2000 acolhia 4 eventos e actualmente acolhe mais de 30, com uma assistência total, estimada em mais de um milhão de espectadores. Apesar dos esforços realizados neste domínio os efeitos gerados foram considerados razoáveis, constituindo um sinal de que, para os inquiridos, o Polis pouco contribuiu para a valorização da imagem turística de Albufeira, para a atracção de mais e novos turistas e muito menos para atrair a população residente à baixa da cidade. Os principais efeitos positivos registados centraram-se na animação turística e na quantidade de eventos, apenas com efeitos negativos expressos pela AHRESP.

A especialização na actividade turística não foi contrariada, procurou-se pelo contrário, cimentar a posição e domínio que Albufeira possui nesta matéria desde há mais de 30 anos. A larga maioria das acçóes implementadas visava munir a cidade dos meios que lhe permitissem desempenhar da melhor forma possível a prestação dos serviços instalados, de 
suporte à actividade turística. Talvez por isso, o domínio Economia e Emprego reuniu os parâmetros com as piores avaliaçóes, sobretudo junto das associaçóes representativas das actividades instaladas, nomeadamente a ACRAL e a AHRESP. Os agentes económicos presentes, nomeadamente os da área da restauração, sendo dos mais críticos ao Polis, foram simultaneamente referenciados pelos inquiridos como os maiores beneficiários de toda a intervenção, fruto da capacidade de atracção gerada e ganhos substanciais em termos de áreas úteis disponibilizadas para, por exemplo, montagem de esplanadas.

Como vimos, as metas de emprego preconizadas neste domínio, dificilmente seriam atingidas. A criação de emprego no domínio do ambiente era uma meta utópica e difícil de concretizar, uma vez que não foi alavancada a qualquer intervençáo ou investimento de monta que a motivasse, da mesma forma que a atracçáo de quadros superiores qualificados enferma o mesmo problema, pois a estratégia favorecia a valorização das actividades já instaladas que promovem trabalho sazonal, precário e pouco qualificado. A própria estrutura e padrão dos estabelecimentos comerciais direccionados para práticas e consumos sazonais, com artigos de uso balnear, impóe procuras diferenciadas ao logo do ano não terá favorecido as avaliaçóes.

Os efeitos gerados pelos meios mecânicos - elevador e escadas rolantes - enquadrados no domínio Mobilidade, Circulaçáo e Estacionamento, apenas foram avaliados negativamente pela AHRESP, por terem impactes positivos limitados a um grupo restrito de 120 restaurantes ou bares face aos 1200 associados que a Associação representa. Ainda neste domínio, um bom sinal do desempenho dos transportes públicos, são as boas avaliaçôes obtidas nos parâmetros de oferta, tarifas, qualidade e adequação de horários e percursos, registadas pela maioria dos inquiridos e em particular pela ACRAL e pelos comerciantes. Em 2004 foram criadas carreiras de transporte público urbano, vulgo Giro, composto por três linhas e paragens em mais de 100 locais. Em 2008, esta carreira transportou mais de 1.160.000 passageiros. As boas avaliaçóes obtidas neste domínio prendem-se essencialmente com a concretização das acçóes e das metas estabelecidas, sustentadas pelo Plano de Circulação, Estacionamento e Transportes de Albufeira, desenvolvido no ano 2002. Entre os melhores e os piores efeitos avaliados encontram-se, respectivamente os meios mecânicos e a oferta de estacionamento.

Ao nível do Património, com excepção da Junta de Freguesia de Albufeira, dos turistas e dos residentes, os restantes inquiridos consideraram que a intervenção Polis pouco valorizou o centro antigo, tendo uma acção irrelevante na conservação ou recuperação do património construído. O parâmetro afecto ao cumprimento do prazo de execução das obras do Polis concretiza a mais expressiva avaliaçáo em muito mau ao nível do efeito causado, apenas o Município de Albufeira o considerou razoável. Lembra-se que o centro antigo de Albufeira enquadrava um dos projectos estruturantes, no entanto, a actuação específica ao nível do património teve acçáo e alcance reduzidos. Embora concretizadas parte das acçóes propostas, estas traduziram-se na recuperação ou reutilização de apenas três edifícios: antiga fábrica de licor de alfarroba e actual parque de estacionamento P5; edifício junto do Museu Municipal que foi integrado por este e antigo edifício do SilverScreen, emblemático espaço da baixa albufeirense que albergará serviços municipais e espaços comerciais. Nas respostas aos inquéritos registaram-se $14 \%$ de mençóes depreciativas face ao estado em que se encontra o património concelhio, juntando-se a este a referência à perda de identidade, dos valores tradicionais e descaracterização da parte antiga da cidade. 
O domínio Governança e Comunicação obteve o maior número de respostas na opção náo sabe/náo responde. A governança mediu-se pela proximidade e contactos da comunidade com os promotores e respectivas tomadas de decisão, envolvimento e participação activa nos fóruns de discussão pública disponíveis e na procura e acesso à informação. $81 \%$ dos inquiridos conhecia ou já tinha ouvido falar do Programa Polis, correspondendo os restantes aos turistas estrangeiros. Contudo, sobre o conhecimento dos objectivos desta estratégia para a cidade de Albufeira, o valor passava para cerca de metade dos inquiridos. Dos inquiridos, cerca de $31 \%$ visitaram o posto de informação do Polis, lembra-se que este universo de inquiridos contava com os representantes das associaçóes e entidades locais, pelo que este valor poderia ser mais baixo do que o registado, não fosse a relação protocolar existente, motivadora dessa visita. Foram esses indivíduos que contribuíram para que cerca de $19 \%$ dos inquiridos tenha participado em sessóes de informaçáo ou esclarecimento promovidas pelo Polis, já que a maioria não participou nem teve conhecimento das mesmas. Nestes dois últimos parâmetros, sem a presença dos representantes das associaçôes e entidades inquiridas, estes valores passariam para apenas $24 \%$ e $11 \%$ dos inquiridos. Respostas maioritariamente negativas foram obtidas nas questóes sobre a consulta ou subscrição de brochuras e newsletters e sobre o conhecimento da mascote Popis, reunindo respectivamente, 65 \% e 64 $\%$ das mesmas. A estas junta-se com uma expressão ainda mais acentuada, $76 \%$ dos inquiridos que afirmam não ter visitado o site www.polisalbufeira.pt (entretanto indisponibilizado). A confirmar esta situaçáo temos a totalidade dos parâmetros deste domínio avaliados de forma negativa. Esta avaliação denota uma falha grave de comunicação e potenciou um clima de desconfiança e mau estar por parte dos inquiridos para com os promotores do Polis, $14 \%$ dos mesmos afirmam que Albufeira foi desrespeitada pelos mentores do Polis. Foi o público escolar o que mais beneficiou das acçóes de sensibilizaçáo ambiental promovidas pela Sociedade Polis. Durante quatro anos lectivos, as intervençóes previstas no Plano Estratégico figuraram nas suas componentes lectivas, foi desenvolvido um manual de suporte para os docentes e promovidos eventos, concursos e sessóes de informação direccionadas especificamente para este público. Pode afirmar-se que em termos de comunicação, registou-se aqui o impacte mais positivo, na dotação de valores e boas práticas ambientais incutidas pelas diferentes ferramentas proporcionadas e sugeridas pela Sociedade Polis à comunidade escolar.

Genericamente, ao nível dos inquiridos e com base na média das respostas aos parametros regista-se uma pior avaliação do que na apreciação global. Veja-se por exemplo a avaliação global muito má obtida pela ACRAL face à apreciação global dada pela mesma entidade que foi razoável. Aliás, na apreciação global, nenhum dos inquiridos atribuiu nota negativa aos efeitos gerados pelo Polis, contudo, o cenário altera-se quando a análise incide nas respostas aos parâmetros avaliados. Neste caso, à ACRAL, que efectua a avaliação mais negativa, juntam-se a AHETA, a AHRESP, a APAL e os comerciantes com avaliações predominantemente negativas. Lembra-se porém que na análise dos efeitos por parâmetros a AHETA registava $47 \%$ de efeitos positivos, avaliação apenas superada pelo Município, Junta de Freguesia e população residente.

Mais de $50 \%$ dos parâmetros avaliados foi considerado pela maioria como tendo produzido efeitos positivos, obtendo a avaliaçáo bom. Globalmente nenhum parâmetro obteve avaliação de muito bom, sendo de destacar porém, o desempenho favorável registado nos meios mecânicos com cerca de $30 \%$ das respostas. Dos efeitos classificados como positivos, aqueles que registaram melhores desempenhos foram a limpeza das praias, quantidade de eventos, animação turística, pedonalização da baixa e atracção de novos turistas e 
visitantes, respectivamente com $54 \%, 53 \%, 49 \%, 48 \%$ e $47 \%$ de respostas a incidir na avaliação bom. Por outro lado, no que respeita às avaliaçóes de efeitos muito negativos, expressas por incidência de respostas em muito mau, destaque para a manutençáo de espaços verdes/jardins e cumprimento do prazo de execuçáo das obras do Polis, respectivamente com $40 \%$ e $33 \%$ das respostas, mas apenas $4 \%$ dos parâmetros. Também negativos, mas com avaliaçóes de mau, surgem a totalidade dos parâmetros contidos no domínio Economia e Emprego e o acesso a informaçôes sobre o Polis. A avaliação negativa incidente ao nível dos efeitos gerados pelo parâmetro da alimentação dos areais das praias prende-se essencialmente pelo incumprimento, à data, das acçóes previstas nesse âmbito. As avaliaçóes de efeitos maus registam-se em $14 \%$ dos parâmetros. Nota para os parametros integrados no domínio Governança e Comunicação cujos efeitos náo foram identificados, face à incidência de respostas na opção não sabe/não responde. Esta resposta ocorreu em $18 \%$ dos parâmetros avaliados.

Ao nível dos contributos efectivos dos domínios para a concretização dos objectivos observamos que os parâmetros incluídos nos domínios Turismo e Animação, Requalificação Urbana e Mobilidade, Circulaçâo e Estacionamento foram os que mais favoreceram o seu alcance. Turismo e Animação foi o domínio com efeitos mais significativos, transversais a seis dos oito objectivos identificados. Economia e Emprego e Património revelaram-se como os domínios com efeitos negativos mais significativos, estendendo-se respectivamente a três e quatro dos objectivos preconizados. A junção do objectivo 8 referente à estratégia de comunicação prendeu-se com o facto de ter sido assumida pelo Programa Polis como área primordial para o sucesso das intervençóes a empreender. Da análise das questóes a ela associadas conclui-se que este objectivo se encontra em desenvolvimento, tendo registado sinais favoráveis à sua prossecução, exemplarmente no trabalho desenvolvido junto da comunidade escolar.

\section{E AGORA ALBUfEIRA?}

Os objectivos, acçôes e metas atingidas em Albufeira por consequência do Programa Polis náo esgotam a política urbana e estratégica da cidade. A dinâmica da cidade exige uma constante atenção, avaliação, intervenção ou reorientação do caminho a seguir para atingir e consolidar objectivos firmes e verdadeiramente profícuos para o território, população e agentes económicos presentes ou a captar. Os processos de planeamento, revestidos de carácter dinâmico, deveráo saber ler os sinais dados por estes, com o intuito de reorientar políticas e actuaçóes em prol de um desenvolvimento harmonioso e que responda às necessidades mais prementes.

Albufeira é uma cidade fortemente marcada pela sazonalidade com a população presente a oscilar, estima-se, entre os 40.000 e os 300.000 indivíduos. A obtenção de níveis de excelência de desempenho da cidade/destino deverá nortear a actuação do Município de Albufeira, que tem a responsabilidade de pensar a cidade em duas dimensóes, a cidade palco da vivência da população que aí habita e labora, espaço de acolhimento de dinâmicas empresariais fortemente especializadas e a cidade destino procurada por milhares de pessoas como local de lazer e diversão, não sendo possível dissociá-las. O crescimento da cidade fomentou o entrosamento dos tecidos urbanos de génese tradicional e de génese turística, dos quais resultou uma cidade turística, na verdadeira acepção do termo. 
Sem o Polis dificilmente o Município empreenderia sozinho, uma intervenção tão pesada, onerosa e com tantas frentes de actuação distintas. A Sociedade Polis cessou as suas funçóes em 2007, cabendo ao Município a liderança dos processos que conduzam à conclusão dos trabalhos e redefinir o rumo e objectivos com vista à obtenção de resultados eficazes, eficientes e duradouros, que contribuam para a distinção e competitividade no quadro regional e nacional. Perante os efeitos registados, estabeleceu-se um conjunto de recomendaçóes e orientaçóes que possam contribuir para a majoração dos efeitos positivos, a minimização dos efeitos negativos, materializando as respostas aos desafios que a cidade enfrentará.

Pensar a cidade pressupóe um acto colectivo e transdisciplinar. O estabelecimento de formas de participação pública, com responsabilidades concertadas e partilhadas por todos, constitui uma boa prática que urge implementar. A co-responsabilização assente em critérios transparentes potenciará o aumento de confiança nos decisores e fomentará melhores desempenhos ao nível da governança. A actuação autónoma e fechada da Sociedade Polis motivou o descontentamento dos agentes locais, constituindo uma crítica recorrente, da qual deverão retirar-se as devidas ilaçóes. A promoção de boas práticas deverá ser vista como uma forma de actuação comum e não como um fim.

Hoje, a cidade é um espaço global, liberal, sem fronteiras físicas impeditivas de formas inovadoras de desenvolvimento, existindo inúmeras oportunidades por fomentar ao nível da sociedade informação. Há que inovar nos produtos, nos processos, nas organizaçóes e no marketing. A renovação dos conceitos de cidade e destino, agarrados a questóes imateriais contribui para a sua afirmação enquanto espaço motor ilimitado, sendo uma matéria que Albufeira terá que aprofundar para manter-se na linha da frente dos principais destinos turísticos do Sul da Europa. A implementação de normas certificadoras do destino, dos produtos e dos serviços prestados, acçóes de marketing urbano e digital, recurso a novas formas de contacto, nomeadamente as redes sociais, procurando outros mercados e públicos podem ser algumas das soluçóes.

Dever-se-á construir uma matriz de monitorização que funcione como um tableau de bord da cidade. O bom desempenho da cidade nos indicadores ou parâmetros de referência, contribuirá para a promoção e atractividade de Albufeira, aliada à prestação de serviços distintos e de qualidade e para a afirmação como um destino notório, competitivo e com clima empresarial favorável. A avaliação conjunta dos indicadores deverá motivar a rectificação ou reorientação da estratégia a seguir, assegurando a sua aproximação à realidade, fazendo da monitorização, um instrumento referencial de suporte nas tomadas de decisão.

O Programa Polis constituiu uma oportunidade globalmente ganha pela cidade, habitantes, visitantes e agentes económicos presentes. O Polis impulsionou de forma decisiva a renovação da cidade e por conseguinte do destino turístico. As obras em geral, o pó, os buracos, as ruas esventradas e os acessos proibidos resultaram numa nova cidade com mobilidade acrescida e com maior capacidade de atracção. Essencial a toda a estratégia, a cidade virou-se para o mar. Os efeitos sentidos foram diferenciados, tanto ao nível dos domínios temáticos como das avaliaçóes realizadas. Os efeitos positivos mais significativos registaram-se na requalificação urbana, na mobilidade e na animação turística. A Renovação da imagem urbana associada aos bons desempenhos na limpeza, à conquista de espaços para fruição colectiva, o acréscimo de áreas pedonais, de áreas de circulação automóvel condicionada, a mobilidade facilitada pelos meios mecânicos e a oferta de múltiplos eventos de natureza cultural e desportiva, motivaram essa renovação. Ficaram por poten- 
ciar oportunidades do foro ambiental e da economia local, presa a padróes de oferta desajustados das novas realidades e procuras.

\section{REFERÊNCIAS BIBLIOGRÁFICAS}

Câmara Municipal de Albufeira 2004, Relatório de Avaliação da Execução do PDM de Albufeira e da caracterização da evolução das condiçóes económicas, sociais e ambientais (Portaria n. 290/2003, de 5 de Abril), Albufeira.

MAOT 2000, POLIS: Programa de Requalificação Urbana e Valorização Ambiental de Cidades - RCM n.o 28/2000 (DR n.o 112, Série I-B de Maio) e anexo a essa Resolução constituído pelo Relatório do Grupo de Trabalho criado pelo despacho n. ${ }^{\circ} 47 / M A O T / 99$ de Sua Ex. ${ }^{a}$ o Ministro do Ambiente e Ordenamento do Território, Lisboa.

MAOT e Câmara Municipal de Albufeira 2000, Plano Estratégico de Albufeira - Viver Albufeira Programa Polis, Lisboa.

MAOT, Polis Albufeira e Câmara Municipal de Albufeira 2003, Albufeira Cidade Turística. Plano de Valorização Turística de Albufeira, Lisboa. 